\title{
DIREITO DA SEGURIDADE SOCIAL NA CONSTITUIÇÃO DE 1988
}

\author{
Sérgio Pinto Martins \\ Juiz Titular da 33“ Vara do Trabalho de São Paulo e \\ Professor Titular de Direito do Trabalho da Faculdade de \\ Direito da Universidade de São Paulo
}

\begin{abstract}
Resumo:
O trabalho versa sobre a reforma da Constituição em decorrência da Emenda Constitucional n. 20/98 e suas consequiências, principalmente as alegações de falta de numerário suficiente para o custeio do sistema de aposentadorias.
\end{abstract}

Abstract:

The Constitution has been reformed by Amendment 20/98 about Social Security. We decide to verify the consequences of this modification, including the allegation of the Government about insuficient money to expense the retires.

Unitermos: Direito da Seguridade Social; reforma.

I. Introdução.

1. A reforma da Previdência Social vinha sendo tentada há vários anos. Foi ao final estabelecida pela Emenda Constitucional n. 20, publicada no Diário Oficial da União, em 16 de dezembro de 1998.

Foram várias as leis ordinárias que visaram a sua implementação, como as Leis ns. 9.701, 9.703, 9.711, 9.715, 9.718, 9.720, 9.732. Muitas dessas leis foram editadas antes da emenda constitucional, em razão de que o art. 246 da Constituição veda a adoção de medidas provisórias para a regulamentação de artigo da Constituição, cuja redação tenha sido alterada por meio de emenda promulgada a partir de 1995. Mais recentemente, o Decreto n. 3.048, de 6 de maio de 1999, que é o regulamento da Previdência Social, faz as adaptações decorrentes da reforma, regulamentando as Leis ns. 8.212 e 8.213 .

A Lei n. 9.876/99 fez várias alterações nas Leis ns. 8.212 e 8.213/91, alterando questões relativas a benefícios e instituindo o fator previdenciário.

Para a análise do tema serão estabelecidos os conceitos de Seguridade Social e Previdência Social e, em seguida, serão examinadas as modificações constitucionais sobre a matéria, visando ao final serem feitas as conclusões necessárias. 
II. Seguridade Social.

2. O Direito da Seguridade Social é um conjunto de princípios, de normas e de instituições destinado a estabelecer um sistema de proteção social aos indivíduos contra contingências que os impeçam de prover as suas necessidades pessoais básicas e de suas famílias, integrado por ações de iniciativa dos Poderes Públicos e da sociedade, visando assegurar os direitos relativos à saúde, à previdência e à assistência social.

De acordo com a previsão do art. 194 da Constituição, a Previdência Social é hoje espécie do gênero Seguridade Social.

\section{Previdência Social.}

3. Previdência vem do latim pre videre, ver com antecipação os riscos sociais na tentativa da composição deles. Previdência Social é a espécie do gênero Seguridade Social, composta de um conjunto de princípios, de normas e de instituições, destinado a estabelecer um sistema de proteção social, mediante contribuição, que tem por objetivo proporcionar meios indispensáveis de subsistência ao segurado e à sua família, quando ocorrer certa contingência prevista em lei.

Os princípios da Previdência Social estão previstos no art. $2^{\circ}$ da Lei n. 8.213. As principais normas são a Lei n. 8.213/91, que trata dos benefícios da Previdência Social, e o Decreto n. 3.048/99, que é o regulamento da Previdência Social. São as principais instituições o INSS e o Ministério da Previdência e Assistência Social. O objetivo da Previdência Social é estabelecer um sistema de proteção social para proporcionar meios indispensáveis de subsistência ao segurado e à sua familia.

O regime previdenciário depende de contribuição por parte do próprio segurado, ao contrário do regime de assistência social, em que o segurado não precisa ter contribuído para fazer jus ao beneficio.

As contingências previstas em lei são as seguintes: doença, invalidez, morte, idade avançada, maternidade, desemprego, conforme previsão do inciso I, do art. 201 da Constituição.

Em verdade, a Previdência Social é eficiente meio de que se serve o Estado moderno na redistribuição da riqueza nacional, visando ao bem-estar do indivíduo e da coletividade, prestado, por intermédio das aposentadorias, como forma de reciclagem da mão-de-obra e oferta de novos empregos.

A Previdência Social consiste, portanto, em una forma de assegurar ao trabalhador, com base no princípio da solidariedade, beneficios ou serviços quando seja atingido por uma contingência social. Entende-se, assim, que o sistema é baseado na solidariedade humana, em que a população ativa deve sustentar a inativa, os aposentados.

IV. Caráter Contributivo.

4. O regime de Previdência Social já era de caráter contributivo, isto é, quem não contribuísse não teria direito a beneficio proporcionado pelo regime geral. 
Acrescenta o art. 201 da Constituição, na redação da Emenda Constitucional n. 20/98, o fato de que há filiação obrigatória. Entretanto, o parágrafo $5 .^{\circ}$ do art. 201 da Constituição admite indiretamente a existência do segurado facultativo, ao mencionar que é vedada a filiação ao regime geral de Previdência Social, na qualidade de segurado facultativo, de pessoa participante de regime próprio de previdência. Logo, não existem apenas segurados obrigatórios ao sistema, mas, também, segurados que podem se filiar facultativamente ao sistema, como a dona de casa, o síndico de condomínio, o estudante e o desempregado.

Passa a haver necessidade de serem observados critérios que preservem o equilíbrio financeiro e atuarial.

\section{Cálculo dos Beneficios.}

5. Previa o art. 202 da Constituição que o cálculo do beneficio seria feito de acordo com a média dos 36 últimos salários-de-contribuição, corrigidos monetariamente mês a mês, sendo feitos reajustes de modo a preservar o seu valor real. O objetivo do constituinte ao estabelecer o citado dispositivo foi de o legislador ordinário não poder alterar ao seu livre alvedrio o cálculo do benefício. Estabeleceu-se uma garantia ao segurado, pois o Governo vinha estabelecendo artificios para o cálculo do beneficio que, na prática, reduziam o seu valor.

Com a Emenda Constitucional n. 20, desapareceu a garantia do segurado contida na Constituição, no sentido de que o benefício deve ser calculado de acordo com os 36 últimos salários-de-contribuição. Os arts. 201 e 202 da Constituição não mais trataram do tema, sendo que o segundo passou a versar sobre Previdência Privada complementar.

Atualmente, apenas existe a previsão do $\S 3^{\circ}$ do art. 201 da Constituição, determinando que todos os salários-de-contribuição considerados para o cálculo do benefício serão devidamente atualizados, na forma da lei.

A nova determinação constitucional implica alteração por lei ordinária do período de cálculo do beneficio. Já se fala num primeiro momento em estender o periodo para sessenta contribuições (cinco anos), dez anos, quinze anos ou num segundo momento em todo o periodo trabalhado pelo segurado. Isso vai trazer um aspecto negativo, em razão de que no início da vida do segurado este tem salário menor e, portanto, o beneficio pode ser reduzido indiretamente.

Especificou-se, também, que é assegurado o reajustamento dos beneficios para preservar-lhes em caráter permanente, o valor real, conforme critérios definidos em lei $\left(\$ 4 .^{\circ}\right.$, do art. 201 da Lei Maior).

O art. 11 da Lei n. 9.711/98 determinou que os benefícios da Previdência Social serão reajustados em junho de cada ano. Anteriormente, as leis previdenciárias ou salariais especificavam o índice a ser utilizado, como IRSM (Lei n. 8.542), IPC-r (Lei n. 8.880). Agora, de propósito não é especificado o índice de correção do benefício, permitindo que o Governo utilize o IQQ ("o índice que eu quero"), podendo ser usado 
o menor índice que apurar a inflação do período, como já ocorreu. As coisas, portanto, são feitas de propósito.

VI. Aposentadoria por Idade.

6. Mencionava o inciso I do art. 201 da Constituição que os planos da Previdência Social cobririam eventos decorrentes de velhice. A atual redação do inciso I do art. 201 da Lei Magna prescreve que a Previdência Social cobrirá eventos decorrentes de idade avançada.

No sistema anterior falava-se em aposentadoria por velhice. A expressão "aposentadoria por idade" surge com a Lei n. 8.213. A denominação utilizada atualmente é mais correta, pois o fato de a pessoa ter sessenta ou 65 anos não quer dizer que seja velha. Há pessoas com essa idade que têm aparência de dez, vinte anos mais moça, além do que a expectativa de vida das pessoas hoje tem atingido muito mais do que sessenta anos. Dai por que se falar em aposentadoria por idade, quando a pessoa atinge a idade especificada na lei.

\section{Aposentadoria no Regime Geral}

7. É assegurada aposentadoria no regime geral de Previdência Social, nos termos da lei, obedecidas as seguintes condições:

a. 35 anos de contribuição, se homem, e trinta anos de contribuição, se mulher;

b. 65 anos de idade, se homem, e sessenta anos de idade, se mulher, reduzido em cinco anos o limite para os trabalhadores rurais de ambos os sexos e para os que exerçam suas atividades em regime de economia familiar, nestes incluídos o produtor rural, o garimpeiro e o pescador artesanal.

Esse dispositivo dá origem à interpretação do ponto e vírgula. Há quem entenda que a regra se refere a duas questões distintas: a primeira da aposentadoria por tempo de contribuição e a segunda da aposentadoria por idade, pois esta era a intenção do constituinte.

A intenção do constituinte, porém, pouco importa na interpretação final da norma, diante da interpretação literal ou gramatical. Vale o que está escrito na norma. $\mathrm{Na}$ norma está escrito que existem duas condições, que são, portanto, cumulativas e não-alternativas. Não se pode, portanto, interpretar o ponto e vírgula como se estivesse escrita a conjunção alternativa $o u$, pois os requisitos são cumulativos, em razão de serem condições que devem ser cumpridas.

Por volta do dia 20 de maio de 1999, a questão foi resolvida, pois o Governo entendeu que são duas condições distintas e não mais passou a exigi-las como cumulativas.

O fator previdenciário foi instituído pela Lei n. 9.876/99, combinando fatores como idade mínima, tempo de contribuição e expectativa de vida do segurado. 
Tem fundamento no art. 201 da Constituição, que determina a observância de critérios que preservem o equilibrio financeiro e atuarial. Exatamente isso foi disciplinado na Lei n. 9.876/99. O STF julgou que o fator previdenciário não era inconstitucional, pois a preservação do equilíbrio financeiro e atuarial está prevista na própria Lei Maior, dando respaldo ao fator previdenciário ser instituído por lei ordinária.

VIII. Aposentadoria Especial.

8. $O \S 1^{\circ}$ do art. 201 da Lei Maior reza que o trabalho em condições especiais que prejudique a saúde ou a integridade física será definido em lei complementar.

Até que a lei complementar a que se refere o citado $\$ 1 .^{\circ}$ seja publicada, permanecem em vigor os arts. 57 e 58 da Lei n. 8.213/91, que tratam da aposentadoria especial (art. 15 da Emenda Constitucional n. 20/98).

IX. Salário-Família.

9. A redação original do inciso XII do art. $7^{\circ}$ da Lei Maior previa "saláriofamilia para os seus dependentes" O beneficio era do segurado, mas decorria do fato de aquela pessoa ter dependentes.

A atual previsão do inciso XII, do art. $7^{\circ}$ da Constituição é de "saláriofamilia pago em razão do dependente do trabalhador de baixa renda nos termos da lei". Determina, ainda, o inciso IV do art. 201 da Constituição o salário-família para os dependentes dos segurados de baixa renda. Agora, somente o trabalhador de baixa renda é que faz jus ao benefício. Reza o artigo 13 da Emenda Constitucional n. 20/98 que até que a lei discipline o acesso ao salário-família, o benefício será concedido apenas àqueles que tenham renda bruta mensal igual ou inferior a $R \$ 429,00$, que, até a publicação da lei, será corrigido pelos mesmos índices aplicados aos beneficios do regime geral de previdência social.

A partir de junho de 1999, o valor do salário-família é de $R \$ 10,31$, para quem ganha mais até $\mathrm{R} \$ 429,00$. Para quem ganha acima desse valor não há direito ao beneficio.

O objetivo da modificação é que no conjunto o valor do salário-família tinha representação para a Previdência Social. Para o segurado de salário mais alto o valor pago era ínfimo e não servia para nada, mas no conjunto representava despesas para o sistema. Assim, apenas o segurado de baixa renda é que passa a ter direito ao benefício.

X. Auxílio-Reclusão.

10. O inciso I do art. 201 da Constituição previa como uma das contingências a ser cobertas pelo sistema de Previdência Social era a reclusão. 
A atual redação do art. 201 da Constituição, conforme a Emenda Constitucional n. 20/98, não mais previu a reclusão como contingência a ser amparada pela Previdência Social. Entretanto, é preciso ser feita a interpretação sistemática com 0 art. 13 da referida emenda que trata do tema.

Determina, ainda, o inciso IV do art. 201 da Constituição o auxílioreclusão para os dependentes dos segurados de baixa renda.

No meu modo de ver, a reclusão nunca foi uma contingência. Não é possivel que a pessoa fique presa e ainda a sociedade como um todo tenha de pagar um beneficio à família do preso, como se este tivesse falecido. De certa forma, o preso é que deveria pagar por se encontrar nessa condição, principalmente por roubo, furto, tráfico, estupro, homicídio etc.

Representa o auxílio-reclusão um beneficio de contingência provocada, razão pela qual não deveria ser pago, pois o preso dá causa, com seu ato, em estar nessa condição. No acidente do trabalho, se o acidente é provocado, o segurado não tem direito ao benefício. $O$ mesmo deveria ocorrer aqui. No auxílio-reclusão, o segurado dá causa à prisão, pelo ilícito que cometeu e faz jus ao beneficio. Logo, não se justifica, sob o meu ponto de vista, a manutenção desse benefício.

A idéia do benefício é o fato de que o preso deixa de ter uma renda. Sua família fica desamparada, razão pela qual deveria ser pago um valor para esse fim.

Determinou o art. 13 da Emenda Constitucional n. 20/98 que até que a lei discipline o acesso ao auxílio-reclusão, o benefício será concedido apenas àqueles que tenham renda bruta mensal igual ou inferior a $R \$ 429,00$, que, até a publicação da lei, será corrigido pelos mesmos índices aplicados aos beneficios do regime geral de Previdência Social. Quem ganha acima de R \$29,00 não tem direito ao benefício.

XI. Salário-Maternidade.

11. No princípio era o empregador quem pagava o salário da gestante no periodo de tempo em que esta ficava afastada para dar a luz. Em conseqüência, a contratação de mulheres era mais escassa, pois o empregador não se interessava em ter esse encargo. Havia necessidade da legislação determinar que o pagamento da licençamaternidade ficaria a cargo da Previdência Social, principalmente como uma forma de incentivar a contratação de mulheres como empregadas'

A Convenção n. 3 da OIT, de 1919, foi promulgada pelo Decreto n. 51.627 , de 18 de dezembro de 1962. Prevê o pagamento das prestações para a manutenção da empregada e de seu filho, que serão pagas pelo Estado ou por sistema de seguro. O Brasil aprovou também a Convenção n. 103 da OIT, de 1952, promulgada pelo Decreto n. 58.020, de 14 de junho de 1966, que reviu a Convenção n. 3, dispondo que "em caso algum o empregador deverá ficar pessoalmente responsável pelo custo das prestações devidas à mulher que emprega" (art. IV, 8). As prestações devidas à 
empregada gestante, tanto antes quanto depois do parto, devem ficar a cargo de um sistema de seguro social ou fundo público, sendo que a lei não pode impor esse ônus ao empregador, inclusive com o objetivo de evitar a discriminação do trabalho da mulher.

Apenas com a edição da Lei n. 6.136, de 7 de novembro de 1974, é que o salário-maternidade passou a ser uma prestação previdenciária, não mais tendo o empregador que pagar o salário da empregada que vai dar a luz. O custeio do saláriomaternidade era de $0,3 \%$ sobre a folha do salário-de-contribuição (art. $4^{\circ}$ da Lei n. 6.136), que foi extinto pela Lei n. $7.787 / 89$, pois ficou englobado no porcentual de $20 \%$ que a empresa deve recolher sobre a folha de pagamento $\left(\S 1^{\circ}\right.$, do art. $3 .^{\circ}$ da Lei n. 7.787$)$. Desde a Lei n. 7.787/89 há custeio específico para o salário-maternidade e o pagamento dos 120 dias. Essa orientação foi repetida no inciso I, do art. 22 da Lei n. 8.212/91.

Disciplinou o inciso XVIII do art. $7 .^{\circ}$ da Constituição que a gestante passa a ter direito a 120 dias de licença-maternidade, sem prejuízo do emprego e do salário.

Limita o art. 14 da Emenda Constitucional n. 20, de 15 de dezembro de 1998, os beneficios do Regime Geral de Previdência Social, que hoje corresponderiam a $\mathrm{R} \$ 1.430,00$. O salário-maternidade também será pago pela Previdência Social, porém no valor máximo de $R \$ 1.430,00$. A dúvida diz respeito a quem ganha acima desse valor.

Criou-se uma polêmica muito grande em torno do salário-maternidade.

O STF, entretanto, concedeu liminar em ação direta de inconstitucionalidade, em relação ao art. 14 da Emenda Constitucional n. 20/98 (ADIn 1.946-5, j. 29.4.99, Rel. Min. Sydney Sanches, DJU 1 10.5.99, p. 30). Entende o STF que o salário-maternidade não está sujeito ao limite de R $\$ 1.200,00$ (especificado na Emenda Constitucional n. 20/98), devendo o INSS pagar o beneficio integralmente, independentemente do valor do salário da trabalhadora gestante. Os ministros do STF afirmaram que a limitação contraria a Constituição, em razão de que a gestante tem garantido o direito à licença maternidade, sem prejuízo do empregado e do salário, com duração de 120 dias (art. 7. ${ }^{\circ}$ XVIII). A decisão ainda não é definitiva, mas a tendência é o STF confirmar a liminar no julgamento do mérito da questão, tanto que antecipou seu ponto de vista.

Com o citado julgamento fica prejudicada a Orientação Normativa n. 10, de 13 de janeiro de 1999, quando estabelece regras para a limitação do saláriomaternidade.

A natureza jurídica do salário-maternidade continua, assim, a ser de beneficio previdenciário, pois é a Previdência Social que faz o seu pagamento. Não se trata de uma prestação de assistência social, por não ser prevista no art. 203 da Constituição, mas de prestação previdenciária incluída no inciso 11 do art. 201 e inciso XVIII, do art. $7 .^{\circ}$ da Constituição ${ }^{2}$

2. No mesmo sentido, o mcu livro Direito da Seguridade Social. $17^{\star}$ cdição. Sào Paulo, Atlas, 2002, pp. 388/9. 
A Lei n. 9.876/99 determinou a alteração do salário-maternidade, que em vez de ser pago pela empresa e descontado da guia de recolhimento da Previdência Social, passou a ser pago diretamente pelo INSS ao empregado. Isso ocasionou uma série de problemas, entre eles a pessoa ficar sem remuneração alguns meses, no período em que o INSS vai verificar o valor a ser pago à segurada. O sistema anterior era melhor, pois o pagamento era feito na própria empresa.

XII. Acidente do Trabalho.

12. Reza o inciso XXVIII do art. $7 .^{\circ}$ da Lei Magna sobre seguro contra acidentes do trabalho, a cargo do empregador, sem excluir a indenização a que está obrigado, quando incorrer em dolo ou culpa.

Não mais menciona o inciso I do art. 201 da Constituição que o acidente do trabalho é uma das contingências a serem cobertas pela Previdência Social.

$\mathrm{O} \S 10$ do art. 201 da Constituição, de acordo com a Emenda Constitucional n. 20/98, dispõe que "lei disciplinará a cobertura do risco de acidente do trabalho, a ser atendida concorrentemente pelo regime geral de previdência social e pelo setor privado"

A lei especificada é a ordinária. Não se exige, portanto, lei complementar. Enquanto não existir lei tratando do assunto, é recebida a Lei n. 8.213/91, que é lei ordinária.

O estabelecimento do regime concorrente entre o INSS e o setor privado vem a ser um retrocesso. A existência de um regime privado outrora não deu certo, pois não atendia às necessidades dos acidentados, principalmente quando se estabelecia a indenização tarifada. Os sindicatos combateram o regime de seguro privado no sistema de acidente do trabalho, dando origem à Lei n. 5.316, de 14.9.67, que passou a estabelecer um regime de responsabilidade objetiva, atribuído ao Estado. A partir.da edição da referida norma, temos um sistema público de acidente do trabalho. A determinação da Constituição implica retrocesso ao sistema anterior a 14.9.67, que não deu certo.

XIII. Tempo de Contribuição.

13. Agora, fala-se em tempo de contribuição e não mais em tempo de serviço para efeito da concessão de aposentadoria.

A Emenda Constitucional n. 20/98 acabou com a aposentadoria por tempo de serviço, que apenas fica mantida num regime transitório, para as pessoas que já estavam no sistema até a data da promulgação da referida emenda.

Para o trabalhador o tempo de contribuição é muito pior, pois antes só precisava provar ter trabalhado, que indicaria o seu tempo de serviço. A anotação na 
CTPS provava o tempo de serviço. Agora, precisa provar que o empregador recolheu a contribuição, o que é um contra-senso.

Passados trinta ou 35 anos será que o trabalhador vai achar a empresa para quem trabalhou para lhe pedir os comprovantes do recolhimento das contribuições para fazer jus ao benefício? Isso não é tarefa do trabalhador, é da fiscalização. Se a fiscalização é inerte e insuficiente, não pode o trabalhador ser apenado pelo fato.

O trabalhador analfabeto ou de poucos estudos vai se lembrar, na data da rescisão de seu contrato de trabalho, de pedir ao empregador cópia do recolhimento das contribuições para no futuro pedir a sua aposentadoria? Com certeza não vai. Como vai conseguir comprovar o tempo de contribuição no futuro? Só Deus sabe.

Felizmente foi mantido o art. 55 da Lei n. 8.213 e o art. 60 do Regulamento da Previdência Social que permitem contar tempo de serviço como tempo de contribuição. Do contrário, o trabalhador seria prejudicado.

XIV. Capitalização.

14. O nosso modelo de Previdência Social é um modelo de repartição simples. Os ativos contribuem para o beneficio dos inativos. Há solidariedade entre as pessoas na cotização do sistema para a concessão do futuro benefício. A massa arrecadada por todos é que paga os benefícios dos trabalhadores.

Objetiva-se fazer um sistema de capitalização individual, em que o segurado vai fazendo a sua contribuição numa conta individual, como se fosse uma conta de poupança.

Não há dúvida de que poupar é necessário para melhor prover o amanhã. Entretanto, há certas pessoas que não têm o que poupar, pois o salário já é irrisório e mal dá para sobreviver. Essas pessoas não vão poupar nada, pois não têm como.

Essa é a razão pela qual o sistema deve ser de repartição, envolvendo a solidariedade entre as pessoas, pois serão poucos os que poderão poupar e muitos os que nada terão, por não terem o que poupar.

Poucos no futuro, se implantado o sistema, terão direito aos beneficios.

XV. Previdência Privada.

15. Pretende-se fazer uma transformação no nosso sistema de Previdência Social. Seria garantido um mínimo ao trabalhador até um certo valor, como, por exemplo, de três salários mínimos. O restante ficaria a cargo da previdência privada complementar.

O sistema assim só vai beneficiar as seguradoras ou bancos que estiverem interessados em atuar na área, por ser muito rendosa.

O sistema público de concessão de beneficios deve ser mantido, ainda que em um nivel básico, pois o sistema privado não se tem mostrado adequado. 
Exemplos são as empresas que passaram a prestar serviços na área e posteriormente faliram, como Capemi, Mongeral e outras, em que o trabalhador pagou vários anos a tais empresas e depois não teve como receber o beneficio na hora em que mais necessitava. Assim, é preferível o sistema público, que pode não ser o melhor, mas pelo menos se sabe que no final do mês e no futuro haverá um recebimento. É a sábia afirmação do caboclo: "é melhor pingado do que seco"

Não adianta querermos importar para o Brasil sistemas como o chileno ou outros. Se a Previdência Social chilena fosse boa, os militares não se teriam excluído de imediato do referido sistema.

A aplicação dos fundos em bolsa é baștante complicada. Basta haver uma oscilação considerável e todo o patrimônio do trabalhador vai por água a baixo. $\mathrm{O}$ economista chileno Orlando Caputo afirma que no seu país corre-se "or risco de que ocorra um desequilibrio entre os ativos é os passivos desses fundos no futuro, já que tiveram prejuizos de cerca de U\$ 4 bilhões com a queda recente das bolsas" (O Globo, 19.4.98).

XVI. Conclusão.

16. Havia necessidade de ser feita uma reforma da Previdência Social, Indubitavelmente, se não fosse feita uma reforma da Previdência Social, chegariamos ao ponto de que dois ativos estariam sustentando um inativo, o que evidentemente iria inviabilizar o sistema em pouco tempo.

Há vários fatores a destacar que implicam a necessidade de reforma. A expectativa de vida média do brasileiro cresceu até por volta de 65 anos, quando por volta de 1960 era de 45/50 anos. Aumentou o número de aposentados, que ficam percebendo benefícios por muito mais tempo, em razão de que a Medicina permite que o homem viva por mais anos. Os trabalhadores obtinham a aposentadoria mais cedo, pois comprovavam o recolhimento necessário. As mulheres tinham vários filhos, que num primeiro momento iam trabalhar e contribuíam para o sistema. O desemprego importa que o trabalhador nada recolha para o sistema, porém dele usufrui sob a forma de seguro-desemprego e sistema de saúde, implicando gastos para o regime.

A reforma, contudo, não trouxe modificações de fundo. Houve uma inquietação muito grande com as mudanças que iriam ocorrer, sem que houvesse uma diretriz fundamental a ser seguida. Como já disse Andrea Calabi: "não há bons ventos para uma nau sem rumo" O projeto estava no Congresso Nacional desde aproximadamente 1992, porém nada do que era preciso foi feito, ou seja, aumentar a fiscalização para diminuir a sonegação, combatendo-a; fiscalizar a concessão de benefícios fraudulentos, que continua ocorrendo; desvios de verbas que são direcionados até para amparo a bancos insolventes, mas não para onde deveria. Tais questões não precisavam de reforma, mas de vontade. Quem quer fazer, faz. Quem não quer, pede, reclama.

Talvez a única mudança de relevo foi a introdução da idade mínima para a pessoa se aposentar, que não tinha previsão na legislação até então vigente, permitindo 
que pessoas se aposentassem até com 37 anos de forma proporcional, como a mulher que tivesse começado a trabalhar com doze anos e somasse 25 anos de tempo de serviço. Realmente era necessário estabelecer um limite de idade para a aposentadoria, que foi fixado em 53 anos para o homem e 48 anos para mulher no regime de transição.

Na prática, o que se constatou é que foram reduzidos direitos previdenciários e dificultada a obtenção de benefícios, como na combinação de tempo de contribuição com idade mínima. O Governo pretende ampliar o período base de cálculo para muito mais do que os 36 salários-de-contribuição. Para o segurado a reforma foi muito pior.

O que mais me preocupa é que não existe estatística confiável e elaborada de forma científica, no sentido de se saber qual é o valor necessário para custear os beneficios do sistema.

Propaga-se um crescente déficit na Previdência Social. Entretanto, o jornal Folha de São Paulo mostrou em 1998, para quem entendeu os gráficos, que o sistema previdenciário direcionado para a área privada não é deficitário. Ao contrário, as receitas são maiores do que os beneficios. O sistema é deficitário a partir do momento em que há junção com os benefícios dos funcionários públicos. Aí sim existe déficit. Então o déficit é do sistema público e não do privado.

Dificil é, inclusive, constatar o déficit mediante dados confiáveis. $O$ trabalhador paga a sua contribuição. A empresa tem contribuições sobre a folha de pagamentos e sobre os rendimentos de segurados que lhe prestam serviços (art. 195, I, a, da Constituição), sobre o faturamento (Cofins e PIS) e sobre o lucro. Há ainda a contribuição sobre a receita dos concursos de prognósticos. É sabido ser considerável a arrecadação de todas as contribuições mencionadas. O Governo divulga o que gasta no sistema, mas não declara quanto efetivamente arrecada, nem soma as contribuições sobre o lucro e sobre o faturamento que são arrecadadas pela Secretaria da Receita Federal e por onde entra o numerário, mas não aparece efetivamente no INSS. Sabe-se que se somarmos a arrecadação do Cofins, do PIS/PASEP, do CPMF e da contribuição sobre o lucro temos, em 1998, aproximadamente R\$ 40 milhões, enquanto que a soma da arrecadação do IPI e do IR importa em R\$ 60 milhões. No ano de 1998 foi arrecadado o valor de R\$ 46 milhões de contribuições previdenciárias das empresas.

Afirma Hugo de Brito Machado que "o exame dos balanços gerais da União revela que as contribuições de previdência, cujo total representava, em 1989 , apenas $34 \%$ da receita tributária, passou a oscilar entre $110 \%$ e $121 \%$ nos anos de 1990 até 1994. Em 1995 a arrecadação dessas contribuições correspondeu a mais de $148 \%$ da receita tributária. Em outras palavras, as contribuições de previdência corresponderam, em 1995, a quase vez e meia de tudo quanto a União arrecadou com todos os seus tributos", 3

Nos dados acima não estão incluídas as contribuições do trabalhador, nem as dos concursos de prognósticos. Raimundo Cerqueira Ally afirma com base no

3. MACHADO, Hugo de Brito. Curso de direito tributário. 19ª edição. São Paulo: Mallaciros, 2001, p. 360 . 
Anuário Estatístico da Previdência Social de 1997 que no ano de 1996 não houve repasse da contribuição sobre o lucro para o INSS. ${ }^{4}$ Onde então está o déficit? Só na parte em que o trabalhador financia o sistema? E as outras receitas mencionadas, não são consideradas? Repito: não existe estatística confiável para se interpretar esses dados.

O segurado não tem segurança jurídica em relação a futura obtenção do beneficio previdenciário. No curso de um período de trinta ou 35 anos várias podem ser as alterações das regras para a aquisição do benefício. É certo que não se pode falar em direito adquirido, mas em mera expectativa de direito. Todavia, a regra do jogo não pode ser modificada no meio do campeonato. O segurado constantemente é apanhado de surpresa, estando em certos casos completamente indefeso. Ora, sua aposentadoria pode chegar até vinte salários mínimos, de acordo com o maior valor teto. Ora, não chega a dez salários mínimos. Como orientar o segurado em relação a esses mecanismos que vão surgindo no curso do tempo? Como explicar para o segurado que contribuía sobre R $\$ 1.430,00$ que hoje o seu benefício é de 8,3 salários mínimos? Ele não entende. Pensa que está sendo ludibriado.

Menciona o Barão de Itararé que "não é triste mudar de idéia. Triste é não ter idéia para mudar". Não há dúvida a respeito da necessidade de mudanças. A inovação é necessária, mas deve ser feita para melhor (reformatio in mellius), para aperfeiçoar e não para pior (reformatio in peius), como em certos casos se viu na recente modificação, principalmente em detrimento do trabalhador.

É uma vergonha escutar que o aposentado é "vagabundo", que não quer trabalhar, que as pessoas idosas deveriam trabalhar mais, principalmente quando já adquiriram o direito a se aposentar e podem decidir livremente o que fazer, quando não têm mais condições de trabalhar. Ou então para receber um valor ínfimo de aposentadoria sequer suficiente para se manter e por esse motivo precisam trabalhar para sobreviver. Infelizmente o aposentado não tem mais de uma aposentadoria, e mais: não tem aposentadoria se não contribuir para adquiri-la, ao contrário de quem fez as afirmações de que não custeou o suficiente para ter direito ao benefício. O bom exemplo deve vir de cima para que possa ser seguido. É necessário, portanto, mais respeito com pessoa que já pagou o necessário para se aposentar, de acordo com a previsão da lei da época dos fatos.

Para concluir, é importante lembrar a afirmação de André Gide de que "todas as coisas já foram ditas, mas como ninguém escuta é preciso sempre recomeçar"

São Paulo, junho de 2002.

4. ALLY, Raimundo Cerqueira. Novas diretrizes para o custeio da previdência social. Tese de doutorado. 1999, p. 50. 